\title{
Proportion of Mothers Enrolled into Mutual Health Organizations and its Influence on the Effective Use of Maternal Healthcare Services in the Kumbo East and West Health Districts of the North West Region of Cameroon
}

\author{
Fortune Wainachi Ndim ${ }^{1,2}$, Okalla Abodo Raphael Therese ${ }^{1}$, Claude Ngwayu Nkfusai ${ }^{3,4 *}$, Nsoh Marius ${ }^{1,4}$, Terrence \\ Beteck Epie ${ }^{3,5}$, Fala Bede ${ }^{3,5}$ and Samuel Nambile Cumber $6,7,8$
}

${ }^{1}$ Department of Public Health, Catholic University of Central Africa, Cameroon

${ }^{2}$ Limona Foundation International, Cameroon

${ }^{3}$ Cameroon Baptist Convention Health Services (CBCHS), Cameroon

${ }^{4}$ Department of Microbiology and Parasitology, University of Buea, Cameroon

${ }^{5}$ Department of Medicine, University of Oxford, United Kingdom

${ }^{6}$ School of Health Systems and Public Health, University of Pretoria Private Bag X323, South Africa

${ }^{7}$ Department of Public Health and Community Medicine (EPSO), University of Gothenburg, Sweden

${ }^{8}$ Faculty of Health Sciences, University of the Free State, South Africa

Submission: August 14, 2019; Published: September 10, 2019

*Corresponding author: Ngwayu Claude Nkfusai, Cameroon Baptist Convention Health Services (CBCHS), Cameroon

\begin{abstract}
Background: The role of a mother as a life giver and a home manager has been very important and is still very important through the generations. Women put themselves through a lot of danger during the whole process of conception, and delivery even post-delivery such that as observed over the past so many years, women have been observed to loss their lives in the process. This work therefore had as main objective to find out the influence of existing mutual health schemes on the use of maternal health care services in Kumbo East and West Health Districts of the North West Region of Cameroon
\end{abstract}

Methods: A quantitative and qualitative cross sectional analytical study was carried out with a prospective and retrospective aspect. A nonprobabilistic sampling technique was applied in which a questionnaire was administered to 385 women from the ages of 16-49 who were either pregnant or had at least a child <5years. Epi info, Stata, Excel were used for data entry and analysis. Chi 2 test and the Fisher's exact test were used in bivariate analysis. The cut off value for significance was considered at $\mathrm{p}<0.05$

Results: A total of 385 women of child bearing age either pregnant or having at least a child under five years old were included in the study both for the quantitative and the qualitative aspect of the study. The proportion of women enrolled into at least a mutual health scheme to those not enrolled is 29.06 is to $70.94 .90 .48 \%$ of the population said $75 \%$ of their health care bills were covered by the MHO unlike $1.9 \%$ of the population which says that only $25 \%$ of their Bills were been covered by the MHO

Conclusion: The study had as general hypothesis "Mutual health organizations have an impact on the maternal health care utilization amongst women in Kumbo East and West Health District". From the findings made from this study, we cannot say convincingly that being registered into the mutual health organization influences the use of maternal healthcare services. In conclusion, we reject the general hypothesis (Ho), hence, mutual health organizations do not have an impact on the use of maternal healthcare services in Kumbo.

Keywords: Proportion; Mothers; Mutual health organizations; Kumbo East and West Health Districts

Abbrevations: ANC: Antenatal Care; MMR: Maternal mortality rate; MHO: Mutual Health organization; WHO: World Health organization; CDC: Center of Disease Control; UNFPA: United Nations Population Fund; KE: Kumbo East; KW: Kumbo West; KEHD: Kumbo East Health District; KWHD: Kumbo West Health District; DMO: District Medical Officer; RDPH: Regional Delegate for Public Health; GIZ: German International Cooperation; Org: Organization 


\section{Introduction}

The role of a mother as a life giver and a home manager has been very important and is still very important through the generations. Women put themselves through a lot of danger during the whole process of conception, and delivery even post-delivery such that as observed over the past so many years, women have been observed to loss their lives in the process. A lot of women have lost their lives in the process of child birth and many others are still doing so. This has through a series of research works been proven. This is in line with what was stipulated in the article Africa in progress [1].

Most of these deaths have been observed to be caused by poorly handled complications probably resulting from deliveries assisted by unskilled personnel as have been observed in most of the rural communities. This view is related to work that was done by (McTavish and Moore.2015) who said that "Every day approximately 1500 women worldwide die due to pregnancy childbirth related complications. Maternal health care use is critical in reducing maternal mortality worldwide "

Globally, there was an estimated 287,000 maternal deaths in 2010 with $99 \%$ of those occurring in developing countries (WHO.2010). Sub-Saharan Africa had the highest maternal mortality ratio (MMR) in 2008 with 640 deaths per 100,000 live births (WHO 2013).

The United Nations report on Trends in Maternal Mortality 2005-2010 categorizes the countries based on their progress towards MDG 5 targets from 1900 to 2010 [2]. One important feature of this report is that it demonstrates progress by providing the average annual percentage change in maternal mortality ratio (MMR) between 1990 and 2010, and categorizes the countries as being 'on track', 'making progress', 'insufficient progress', or 'on progress' made over time. Six countries viz. Ethiopia, Madagascar, and Uganda had <350 MMR in 2010, made sufficient progress towards achieving their MDG 5 targets, maintained an average annual reduction rate of $>4.5$, and had available Demographic and HEALTH Surveys (DHS) data for 2010 or 2011. The other three countries viz. Cameroon, Zambia and Zimbabwe had >550 MMR in 2010, made insufficient or no progress towards achieving their MDG 5 targets, maintained an average annual reduction rate of < 1.5, and DHS data available for 2010 or 2011.

Another piece of work done by Abeje G [3] laid emphasis on the fact that « Pregnancy and childbirth related morbidity and mortality are serious problems worldwide especially in the less developed world. Globally about 287000 maternal deaths occurred in 2010 and the less developed countries accounted for $99 \%$ of the global maternal death [4]. Cameroon has been observed as well to have a high rate of maternal mortality in Africa as compared to other African countries with a death ratio of 782 deaths per 100000 live births. (EDS MICS 2011) accessibility to the various facilities for maternal healthcare that have been put at the disposal of the community has been observed to be a big problem. So many women especially women in the rural areas have the facilities but cannot utilize them due to some constraints one of which is financial (Gaston Sorgho 2016). Countries such as Cameroon with the out of pocket system of healthcare purchase has posed a very heavy financial burden on its population making it difficult for the poor to access the available healthcare hence most women who are pregnant decide either to use the traditional unskilled method of delivery or come to purchase healthcare only at term hence making it difficult for any underlying complications which could probably show up to be identified on time.

This work therefore had as main objective to find out the influence of existing mutual health schemes on the use of maternal health care services in Kumbo East and West Health Districts of the North West Region of Cameroon. The study population was pregnant women and women with children less than 5 years who were registered into a mutual health scheme as well as those who were not enrolled.

\section{Methods}

\section{Study design, Sitting and Population}

A quantitative cross sectional analytical study was carried out with a prospective aspect in the Kumbo East and West Health Districts of the North West Region. This study was carried out in the Kumbo East and West Health Districts which both consist of urban and rural areas. Kumbo East Health District (KEHD) is one of the 19 health districts in the North West Region same like Kumbo West Health District (KWHD). KEHD covers a total population of 179932 inhabitants and a surface area of $1087 \mathrm{~km} 2$. KWHD covers a population of 99125 inhabitants and a surface area of $1025 \mathrm{~km} 2$.

\section{Selection Criteria}

\section{Inclusion criteria}

a) Women of childbearing age 16-49 years having a child below 5years presently.

b) Women currently pregnant during the time of the study

c) Women who accepted to participate in the study

\section{Exclusion criteria}

a) Those who refused to participate in the study

b) Women who were not resident in the health area of study during the time of the study.

\section{Sample size and sampling}

The sample size was calculated using Fisher's formula;

$$
\text { Sample size }=\frac{z 2 x p(1-p)}{e 2}
$$

Where

$\mathrm{P}=$ Prevalence of the outcome (taken as $50 \%$ given that conventionally was not known.) 
$\mathrm{E}=$ margin of error at $95 \%$ giving as 0.05

$\mathrm{Z}$ score $=1.96$

$\mathrm{n}=$ Sample population

Sample size $=\frac{1.962 \times 0.5(1-0.5)}{0.052=0.0025}$

$\mathrm{N}=385$

From the calculation, a sample size of 385 participants was to be administered in the kumbo East and West Health Districts.

\section{Data Collection}

Data was collected using a self-administered well-structured questionnaire which was filled by the respondents and returned. Prior to use in the study participants, pre-testing was done at the Biyem Assi Health District Yaounde so as to ensure that the questionnaire would be correctly understood by women in the field. About twenty pregnant women and women with at least a child less than five years were interviewed using the questionnaire that had been designed for this study. After the pre-test, adequate modifications were made on the questionnaires where necessary. These corrections were made to ensure that instrument was ready for use. It was estimated that; each questionnaire could be administered for 30-45 minutes after the pretest.

A total of 385 questionnaires were administered to pregnant women between the ages of 16-49 years of age and mothers with children under five years of age. Both those who were registered in a mutual health scheme and those not registered in any mutual health scheme were enrolled in this study.

\section{Data Analyses}

Computing the socio-demographic characteristics of women of child-bearing age 16-49 such as age, level of education, occupation and marital status, using categorical variable frequencies. For the bivariate analysis, the dependent variable was maternal healthcare utilization and the independent variable mutual health. Other independent variables include ANCI, ANC4, Tetanus injection in pregnancy, Delivery, General healthcare utilization were computed each with the dependent variable. Cross tables were done, Chi square test and the Fisher's test was used to test for statistical significance and association. The Software that was used to analysis the data Epi info version 3.0 and version7.0 as well as STATA and Microsoft Excel.

\section{Ethical Consideration}

Ethical clearance was obtained from the school of health science Ethical Review Board, UCAC. An authorization letter was collected as well from both from the Director of the catholic university of central Africa and the Regional delegate of Northwest region to conduct the study at the Kumbo East and West Health Districts. Authorization forms were obtained as well from the District chiefs of service for both Kumbo East and Kumbo West. Consent and the information forms were also being made available for the respondents and information gotten during the study was be kept confidential and use for the purpose of research only. Names of respondents were not taken for the purpose of confidentiality. Rather codes were used in order to ensure their confidentiality. At the end of the study, the questionnaire was burned to ensure that there is no disclosure of the information that obtained from the respondents.

Result

\section{Socio- Demographic characteristics of the population}

Table 1: Socio- Demographic characteristics of the population.

\begin{tabular}{|c|c|c|c|}
\hline Variable & Category & Frequency & $\%$ \\
\hline \multirow{6}{*}{ Age } & $16-20$ & 36 & 9.73 \\
\hline & $21-25$ & 87 & 23.51 \\
\hline & $26-30$ & 113 & 30.54 \\
\hline & $31-35$ & 67 & 18.11 \\
\hline & $36-40$ & 49 & 13.24 \\
\hline & $>40$ & 18 & 4.86 \\
\hline \multirow{3}{*}{ Marital status } & Married & 283 & 73.51 \\
\hline & Single & 92 & 23.9 \\
\hline & Divorced & 10 & 2.6 \\
\hline \multirow{6}{*}{ Religion } & Catholic & 227 & 59.11 \\
\hline & Baptist & 30 & 7.81 \\
\hline & Presbyterian & 59 & 15.36 \\
\hline & Muslim & 57 & 14.84 \\
\hline & Others & 6 & 1.56 \\
\hline & None & 5 & 1.3 \\
\hline \multirow{4}{*}{$\begin{array}{l}\text { Educational } \\
\text { status }\end{array}$} & First school & 213 & 56.2 \\
\hline & $\begin{array}{c}\text { Secondary } \\
\text { school }\end{array}$ & 92 & 24.27 \\
\hline & High school & 59 & 15.57 \\
\hline & University & 15 & 3.96 \\
\hline \multirow{4}{*}{$\begin{array}{l}\text { Professional } \\
\text { status }\end{array}$} & Worker & 67 & 18.41 \\
\hline & House wife & 164 & 45.05 \\
\hline & Farmer & 131 & 35.99 \\
\hline & others & 2 & 0.55 \\
\hline
\end{tabular}

A total of 385 women of child bearing age either pregnant or having at least a child under five years old were included in the study both for the quantitative and the qualitative aspect of the study. The main results of the study are presented in two main sections which are; quantitative results and qualitative results presentation (Table 1).

\section{Proportion of women enrolled into at least into a mutual health scheme}

The proportion of women enrolled into at least a mutual health scheme to those not enrolled is 29.06 is to 70.94 (Table 2). 
Table 2: Proportion of women enrolled into at least into a mutual health scheme.

\begin{tabular}{|c|c|c|c|}
\hline $\begin{array}{c}\text { Enrolled Into a } \\
\text { MHO Scheme }\end{array}$ & Frequency & Percent (\%) & $\begin{array}{c}\text { Cum. Percent } \\
\text { (\%) }\end{array}$ \\
\hline Enrolled & 111 & 29.06 & 29.06 \\
\hline Not enrolled & 271 & 70.94 & 100 \\
\hline Total & 382 & 100 & 100 \\
\hline
\end{tabular}

\section{The percentage of bills covered by the MHO}

The percentage of the health care service bills that are covered by MHO From the findings gotten, $90.48 \%$ of the population said $75 \%$ of their health care bills were covered by the MHO un like $1.9 \%$ of the population which says that only $25 \%$ of their Bills were been covered by the MHO (Table 3).

Table 3: The percentage of bills covered by the MHO.

\begin{tabular}{|c|c|c|c|}
\hline $\begin{array}{c}\text { Percentage } \\
\text { Covered }\end{array}$ & Frequency & Percent(\%) & $\begin{array}{c}\text { Cum. Percent } \\
\text { (\%) }\end{array}$ \\
\hline $75 \%$ & 95 & 90.48 & 90.48 \\
\hline $50 \%$ & 8 & 7.62 & 98.1 \\
\hline $25 \%$ & 2 & 1.9 & 100 \\
\hline Total & 105 & 100 & 100 \\
\hline
\end{tabular}

Displays the level of health service use amongst mothers who are not enrolled to those enrolled in a scheme

This indicates that health service use is more effective amongst those enrolled into a scheme as its seen that out of $88.39 \%$ who effectively use the healthcare service, only about $8.03 \%$ do not effectively use it. While on the other hand for those who are not enrolled, out of $87.91 \%$ that use the health service effectively, up to about $12.09 \%$ of these women do not use the healthcare service effectively which is a little elevated compared to the former (Table 4).

Table 4: Displays the level of health service use amongst mothers who are not enrolled to those enrolled in a scheme.

\begin{tabular}{|c|c|c|c|c|}
\hline & $\begin{array}{c}\text { Enrolled } \\
\text { in Mutual } \\
\text { Health } \\
\text { (112 Wom- } \\
\text { en) }\end{array}$ & $\begin{array}{c}\text { Percentage } \\
\text { Use (\%) }\end{array}$ & $\begin{array}{c}\text { NOT } \\
\text { Enrolled } \\
\text { in Mutual } \\
\text { Health } \\
\text { (273 Wom- } \\
\text { en) }\end{array}$ & $\begin{array}{c}\text { Percentage } \\
\text { Use (\%) }\end{array}$ \\
\hline $\begin{array}{c}\text { Maternal } \\
\text { health care } \\
\text { utilization }\end{array}$ & 99 & 88.39 & 240 & 87.91 \\
\hline $\begin{array}{c}\text { No Maternal } \\
\text { health care } \\
\text { utilization }\end{array}$ & 9 & 8.03 & 33 & 12.09 \\
\hline
\end{tabular}

The Influence of being registered in a MHO on the utilization of ANC services

The influence of being registered into a mutual health scheme on the use of ANC services.

\section{P-value (Fisher's exact test $)=0.683$}

With the above P-value, it shows that there is no association between being enrolled in the mutual health scheme and the use of ANC services. Hence being enrolled into a Mutual health scheme cannot be pointed out as so much of an encouraging factor for the use of ANC services given that not many mothers on the other hand are even enrolled (Table 5).

Table 5: The Influence of being registered in a MHO on the utilization of ANC services.

\begin{tabular}{|c|c|c|c|c|c|c|c|}
\hline \multicolumn{1}{|c|}{ Utilisation of ANC Service } \\
\hline $\begin{array}{c}\text { Enrolled in a } \\
\text { Scheme }\end{array}$ & ANC 1 & ANC 2 & ANC 3 & ANC 4 & More & None & Total \\
\hline Enrolled & 11 & 8 & 11 & 3 & 3 & 5 & 41 \\
\hline Frequency (\%) & 26.83 & 19.51 & 26.83 & 7.32 & 7.32 & 12.2 & 100 \\
\hline Not enrolled & 27 & 20 & 29 & 16 & 18 & 22 & 132 \\
\hline Frequency (\%) & 20.45 & 15.15 & 21.97 & 12.12 & 13.64 & 16.67 & 100 \\
\hline TOTAL & 38 & 28 & 40 & 19 & 21 & 12.14 & 17.61 \\
\hline Frequency (\%) & 21.97 & 16.18 & 23.12 & 10.98 & 12.14 & 100 \\
\hline
\end{tabular}

\section{The influence of being registered in a MHO on the utilization of assisted delivery services}

Table 6: The influence of being registered in a MHO on the utilization of assisted delivery services.

\begin{tabular}{|c|c|c|c|}
\hline & Assisted Delivery & Total \\
\hline Enrolled in a Scheme & Assisted Delivery & Not Assisted & 63 \\
\hline Enrolled & 60 & 3 & 100 \\
\hline Frequency (\%) & 95.24 & 4.76 & 133 \\
\hline Not enrolled & 127 & 6 & 100 \\
\hline Frequency (\%) & 95.49 & 4.51 & 196 \\
\hline TOTAL & 187 & 4.59 & 100 \\
\hline Frequency (\%) & 95.41 & 9 \\
\hline
\end{tabular}


The influence of being registered in a MHO on the utilization of assisted delivery services P- Value (Fisher exact test) $=0.5968608087$. With the above P-value, it shows that there is not association between been enrolled in a mutual health scheme and the use of assisted delivery given that majority of the women are not enrolled into the mutual health and they still use the services well as out of $100 \%$ of those who responded to the question that were not enrolled,95.49\% were gave birth assisted by health personnel and only $4.51 \%$ of the population did not (Table 6).

\section{The influence of being registered in a MHO on the utilization of hospital consultation services}

The influence of being registered in an MHO on the utilization of hospital consultation services

$$
\text { P-value (Fisher exact test })=0.1685715030
$$

There is therefore no association between being registered into a Mutual health scheme and health care service consultation (Table 7).

Table 7 : The influence of being registered in a $\mathrm{MHO}$ on the utilization of hospital consultation services.

\begin{tabular}{|c|c|c|c|}
\hline \multicolumn{4}{|c|}{ General Consultation } \\
\hline Enrolled in a Scheme & Consulted & Did not Consult & Total \\
\hline Enrolled & 49 & 12 & 61 \\
\hline Frequency (\%) & 80.33 & 19.67 & 100 \\
\hline Not enrolled & 93 & 35 & 128 \\
\hline Frequency (\%) & 72.66 & 27.34 & 100 \\
\hline TOTAL & 142 & 47 & 189 \\
\hline Frequency (\%) & 75.13 & 24.87 & 100 \\
\hline
\end{tabular}

\section{Discussion}

One of the objectives was to find out the proportion of women that are enrolled into mutual health organization to those who are not registered. From the findings gotten from the field, 29.06\% of the women were enrolled into at least a mutual health scheme while a greater population of the women was not enrolled like about 70.94\%. A lot of factors contributed to their reason for not being enrolled into any mutual health scheme. Out of the $70.94 \%$ of the women who were not enrolled into any mutual health scheme, $41.61 \%$ of them said the reason to which they were not enrolled was because they hadn't money to register, $36.13 \%$ of them said that they were still to consider getting enrolled while $16.42 \%$ of the women said they hadn't the slightest knowledge on the existence of the mutual health organization and $2.55 \%$ said they didn't see the importance of being enrolled. From the above results, the main reason to which the respondents were poverty which has contributed greatly to their inability to get enrolled into any scheme. This is given that a huge sum of money is needed in order to be part of a MHO and this therefore in a way excludes the poor community who have farming as their main source of income and hence have very little left in their pockets for the upkeep of their families. This finding are contradictory to the findings made by Ranson et al. [5]. Their findings stated that MHOs are inclusive of the poorest. On the other hand, the findings are in line with those made by Bennett et al. [6]; Jütting [7]; De Allegri et al. [8]. They found out that MHOs tend to exclude the poor.

This exclusion is through the fact that enrollment into these schemes needs at least from the number of four to 10 people for a start requiring a minimum amount of 20000 frs for registration and most of the time, all of the people that make up this group are usually from the same family, making it very heavy to remove that amount of money needed to register hence, they decide not to register and hence it becomes harder on them when they finally get sick and are expected to pay heavy bills.

Another factor is associated to the educational level. A P-value of 0.044 was obtained using the Fisher exact test which indicated that there was an association between the educational level of the population and their enrollment into the mutual health scheme. These findings are in line with those made by (Slavea G chankova, Sara Sulzbach (2006) who stated that Education of household head is also positively associated with MHO enrolment.

Given that $54,5 \%$ of the sample population was made up of first school leavers, and $23.9 \%$ secondary school leavers this made $78.4 \%$ of the sample population people who had no valid educational backing that could in turn help them secure a good job that will in turn give them a good financial state, it made them limited to peasant farming and other menial jobs. which gave them just enough money to put food on their table.

$16.42 \%$ of the population that was not enrolled into any scheme was made up of these women who hadn't any idea about the existence of the organization. This probably could be associated to poor sensitization on the part of the technical team.

Given that GIZ withdrew their support from the HIV program in Cameroon, their support to the Mutual health scheme was withdrawn as well. In kumbo, it made the contributions that came from the public the only source of revenue that they used to run the organization. This generally made the running of the organization very difficult as some of the members of the community started withdrawing especially those who were on HIV treatment being supported by GIZ, and those who felt that the organization was not respecting the $\%$ that had been promised for the payment 
of bills. With the limited finance available for the running of the organization due to no external support, payment of the field staff became difficult so very little community mobilization was done and the population develop cold feet.

The respondents as well said that some of them left the organization because they felt that they gave their money and never used it. some of the respondents in their words said that "it feels like each time one registers into the mutual health scheme, he stops being sick" this actually served as a discouraging factor to a number of them considering the fact that they hadn't been well oriented from the start.

Additionally, a good number of the respondents $2.55 \%$ said they did not see the importance of being enrolled. They were positive about the fact that they will rather go straight to the hospital and use money from their pockets to pay for their health care bills rather than go put the money in some organization in the name of "securing for your future". They will as well prefer to invest in a business rather than waste their money. This is in line with the theory of planned behaviour Ajzen and Fishbien (1980) which says that The best predictor of behaviour is intention. Intention is the cognitive representation of a person's readiness to perform a given behaviour, and it is considered to be the immediate antecedent of behaviour.

Another group of people were the Muslims who make up $14.84 \%$ of the sample population. This group of people were not enrolled because they said it was against their religion to save up money for future sickness. It was actually considered a sin and hence their faithful's did not get enrolled and for the few that got enrolled, ended backing out up out of fear.

\section{Conclusion}

In most African countries, including the low-income, poor and rural populations have low utilization and coverage rates for key preventive and primary curative interventions. Because of their poverty, these populations tend to suffer more health problems; because of their health problems, they tend to be poorer [9]. There are many reasons for low utilization of priority health services in Africa, including poor physical and financial access to care, socioeconomic factors, cultural factors and perceptions about the quality of care [10]. with respect to the existence of Mutual health organizations in the community, which are out to help in risk sharing and help in the increase of access of the community to quality health care service, the researcher decided therefore to find out if the existing mutual health organizations do have any impact on the use of maternal health care services [11-15]. A univariate and bivariate analysis was done and all the p-values gotten but for one which was the influence of educational status on the enrolment into mutual health was significant. There was no clear association found between being enrolled in a mutual health scheme and using either the ANC service, assisted delivery, General consultation services effectively [16-20]. This is because, it was clearly seen that regardless of the fact that very few people were enrolled in the scheme, the fact that the others were not enrolled did not affect the level of their healthcare service use. The level of healthcare service use was almost the same amongst those who were enrolled as well [21-25].

The study had as general hypothesis "Mutual health organizations have an impact on the maternal health care utilization amongst women in kumbo East and West Health District". From the findings made from this study, we cannot say convincingly that being registered into the mutual health organization influences the use of maternal healthcare services. In conclusion, we reject the general hypothesis (Ho), hence, mutual health organizations do not have an impact on the use of maternal healthcare services in kumbo [26-30].

\section{What is Already Know About the Topic}

a) Community-based health insurance schemes in developing countries:facts,problems, and perspectives [3135].

b) Predicting Health Behavior. Search and Practice with Social Cognition Models

c) Determinants of financial stability of mutual health organizations in the Thies Regions of Senegal:household survey component House hold survery component [36-40].

\section{What this Study Adds}

a) There are many reasons for low utilization of priority health services in Africa, including poor physical and financial access to care, socioeconomic factors, cultural factors and perceptions about the quality of care [41-45].

b) The level of healthcare service use was almost the same amongst those who were enrolled as well

c) Mutual health organizations have an impact on the maternal health care utilization amongst women in kumbo East and West Health District [46-49].

\section{Authors contribution}

WFN, OART, CNN, NM, TBE, FB and SNC designed the study and were involved in all aspects of the study. WFN, OART, CNN, NM, TBE, FB and SNC contributed to scientifically reviewing the manuscript for intellectual inputs and review. All authors reviewed the final manuscript and agreed for submission.

\section{Acknowledgement}

We are grateful to all the women who participated in this research.

\section{References}

1. Progress AI (2010) Maternal health: investigating in the lifeline of healthy societies and economies. Africa in progress panel, Geneva, Switzerland.

2. WHO (2012) Trends in maternal mortality: 1990-2010 Tech. Rep, WHO UNICEF,UNFPA and the World Bank Estimates. Geneva, Switzerland. 
3. Abeje G (2014) Factors associated with institutional delivery service utilization amongst mothers in Bahir Dar city administraion, Amhara region, Ethiopia 11: 22.

4. Tey NP (2013) Correlates of and barriers to the utilization of health services for delivery in south Asia and sub-saharan africa. science world Journal, pp. 1-12.

5. Ranson M, Sinha T, Chatterjee M, Acharya A, Bhavsar A, et al. (2006) Making health insurance work for the poor: learning from selfemployed womens association (SEWA)community-based health insurance scheme in india. Soc Sci Med 62(3): 707-720.

6. Bennet S (1998) Health insurance schemes for peple outside formal sector employment. Geneva world Health Organization, Switzerland.

7. Jütting J (2004) Community-Based health insurance schemes improve poor people's access to health care? Evidence from Rural Senegal, Senegal 32: 273-288.

8. Van D, O'Donnell O, Rannan-Eliya R, Somanathan A, Adhikari SR, et al. (2006) Effect of payments for healthcare on poorverty estimates in 11 countries in Asia: an analysis of household survey data. Lancet 368(9544): 1357-1364.

9. Sachs JD, Ahluwalia IJ, Amoako KY, Aninat E, Cohen D, et al. (2001) Macroeconomics and health: investing in health for economic development: report of the Commission on Macroeconomics and Health. World Health Organization, Geneva, Switzerland.

10. Ndiaye P, Dia AT, Diedgiou A, Dieye EH, Dione DA, et al. (2005) Sociocultural determinants of the lateness of the first prenatal consultation in a health district in Senegal. Sante Publique 17(4): 531-538.

11. Atim C (1999) Social movements and health insurance:a critical evaluation of voluntary, non-profit insurance schemes with case studies from Ghana and Cameroon. Soc Sci Med 48(7): 881-96.

12. Ajzen I (1985) From intentions to actions: A theory of planned behavior In: J Kuhl, J Beckman [Eds.], Action-control: From cognition to behavior, Springer, pp. 11-39.

13. Ajzen I (1987) Attitudes, traits, and actions: Dispositional prediction of behavior in personality and social psychology. In: L Berkowitz [Ed.] Advances in experimental social psychology 20: 1-63.

14. Ajzen I (1988) Attitudes, personality, and behavior. Open University Press \& Chicago, Milton-Keynes, England.

15. Ajzen I (1991) The theory of planned behavior. Organizational Behavior and Human Decision Processes 50: 179-211.

16. Beaglehole R, Bonita R (2006) Basic Epidemiology. In: (2 ${ }^{\text {nd }}$ edn), Cambridge University Press, UK.

17. Cameroon T (n.d) Cameroon health insurance options.

18. Carrin G (2003) Community-based health insurance schemes in developing countries: facts, problems, and perspectives. Geneva World Health organization, Switzerland.

19. Criel B, Kegels G (1997) A health insurance scheme for hospital Care in Bwamanda distric, Zaire: lessons and questions after 10 years of functioning. Trop Med Int Health 2(7): 654-672.

20. Conner M, Norman P (1996) Predicting Health Behavior. Search and Practice with Social Cognition Models. Open University Press, UK.

21. Devadasan N, Criel B, Damme V, Ranson MK, Stuyft VDP, et al. (2007) Indian community health insurance schemes provide partial protection against catastrophic health expenditure. BMC Health Serv Res 7: 43.

22. Diop F (2001) Determinants of financial stability of mutual health organizations in the Thies Regions of Senegal: household survey component House hold survery component. Partners for Health Reform Plus Project, Abt Associates Inc, USA.
23. Ekman B (2004) Community-Based health insurance in Low-income countries: a systematic review of evidence. Health Policy Plan 19(5): 249-270.

24. Fishbein M, Ajzen I (2005) Theory-based behavior change interventions: Comments on Hobbis and Sutton. J Health Psychol 10(1): 27-31.

25. Glanz K, Rimer BK, Lewis FM (2002) Health Behavior and Health Education. Theory, Research and Practice. Wiley \& Sons, San Fransisco, USA.

26. Gilson L (1997) The lessons of user fee experience in Africa. Health Policy Plan 12(4): 273-285.

27. Hope R (2003) Paying in potatoes: community-Based insurance for Rural and informal sector. Lancet 362(9386): 827-829.

28. Jakab M, Krishnan C (2001) Community involvement in health care financing: a survey of literature on the impact, strenghts and weaknesse. World Bank Health, Nutrition and Population Discussion Paper, Washington, DC World Bank, USA.

29. Alvarez JL, Gil R, Hernández V, Gil A (2009) Factors associated with maternal moratlity in subsaharan africa: an ecological study. BMC health 9: 462.

30. Jowett M (n.d) Do informal risk sharing networks crowd out public voluntary health insurance? evidence from Vietnam, China.

31. Birmeta K, Dibaba Y, Woldeyohannes D (2013) Determinants of maternal healthcare utilization in Holeta town, Cental ethopia. BMC Health Serv Res 13: 256.

32. Miller K (2005) Communications theories: perspectives, processes, and contexts. McGraw-Hill, New York, USA.

33. Sheppard BH, Hartwick J, Warshaw PR (1988) The theory of reasoned action: A meta-analysis of past research with recommendations for modifications and future research. Journal of Consumer Research 15: 325-343.

34. Lee JW (2005) Public health is a social issue. Lancet 365(9464): 10051006.

35. Moyer CA, Dako-Gyeke P, Adanu RM (2013) Facility-based delivery and maternal and early neonatal mortality in sub-saharan Africa: Aregional review of literature. Afr J Reprod Health 17(3): 30-43.

36. Musau S (1999) Community-based insurance; experiences and lessons learned from East and Southern Africa. Partnership for health Reform, Abt Associates inc, USA.

37. Ndiaye P, Dia AT, Diedgiou A, Dieye EH, Dione DA, et al. (2005) Sociocultural determinants of the lateness of the first prenatal consultation in a health district in Senegal. Sante Publique 17(4): 531-538.

38. Organization(ILO) (2002) Extending social protection in health through community based health organizations: evidence and challenges. Discussion paper Geneva, Switzerland.

39. Palmer N, Mueller DH, Gilson L, Mills A, Haines A, et al. (2004) Health financing to promote access in low income settings-How much do we know? Lancet 364(9442): 1365-1370.

40. Preker AS, Carrin G, Dror D, Jakab M, Hsiao W, et al. (2002) Effectiveness of community health financing in meeting the cost of illness. Bull World Health Organ 80(2): 143-150.

41. Schneider P, Diop F (2001) Impact of prepayment pilot on health care utilization and financing in Rwanda: findings from final household survey. Partners for health Reform Plus project, Abt Associates inc, USA.

42. Stretcher L, Victor J, Irwin M, Rosenstock J (1997) The health belief model. In Andrew Baum. Cambridge handbook of psychology, health 
and medicine. Cambridge, Cambridge University Press, UK, pp. 113117.

43. Tey NP (2013) Correlates of and barriers to the utilization of health services for delivery in South Asia and Sub-Saharan Africa. The Scientific World Journal, USA.

44. Haddad S, Ridde V, Yacoubou I, Mák G, Gbetié M, et al. (2012) An evaluation of the outcomes of mutual health organizations in Benin. Plos one 7(10): e47136.

45. Wasamundi (n.d) Mutual health organization. Molyko-Buea, Cameroon.
46. WHO (2001) Macroeconomics and Health insurance for economic development. Geneva World Health Organization: Report of the Commission on Macreconomics and Health, Switzerland.

47. WHO (2014) Trends in maternal mortality.

48. Xu K, Evans DB, Kawabata K, Geraldine R, Klavus J, et al. (2003) Household catastrophic health expenditure: a multicountry analysis. Lancet 362(9378): 111-117.

49. Zere E, Kirigia JM, Duale S, Akazili J (2012) Inequities in maternal and child health outcomes and interventions in Ghana. BMC public health 12: 252 .

\section{Your next submission with Juniper Publishers will reach you the below assets}

- Quality Editorial service

- Swift Peer Review

- Reprints availability

- E-prints Service

- Manuscript Podcast for convenient understanding

- Global attainment for your research

- Manuscript accessibility in different formats

( Pdf, E-pub, Full Tsext, Audio)

- Unceasing customer service

Track the below URL for one-step submission https://juniperpublishers.com/online-submission.php 